\title{
O LUGAR ONDE A ESTRUTURA SE DESCONTROLA
}

\author{
Rogério Lima*
}

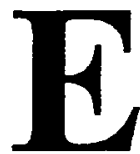

xiste a possibilidade da fundação de uma pertinência da leitura? Qual a função do desejo no estabelecimento dos protocolos de leitura? É possível uma relação recalcada entre o leitor e o livro? Qual é o lugar do sujeito na cena da leitura? Procuramos responder essas questões a partir da análise do texto "Da leitura", de Roland Barthes, publicado em $O$ Rumor da língua (1988). O texto, inicialmente, foi escrito para a Writing Conference de Luchon, 1975. Publicado no Français Aujourd 'hui, 1976.

Segundo Barthes, enquanto leitores, muitas coisas nos unem a começar por essas perguntas comuns que nos fazemos, cada um de seu lugar: $O$ que $e$ ler? Por que ler? Como ler? Ele confessa-se desamparado no que diz respeito ao estabelecimento de uma doutrina sobre a leitura. Esse desamparo chega, às vezes, à beirar a dúvida:

Nem sei se é preciso ter uma doutrina da leitura; não sei se a leitura não é, constitutivamente um campo plural de práticas dispersas, de efeitos irredutíveis, e se, conseqüentemente, a leitura da leitura, a Metaleitura, não é mais do que um estilhaçar-se de idéias, de temores, de desejos, de gozos, de opressões [...].

* Universidade Federal do Paraná. 
Barthes não busca reduzir esse desamparo: ao contrário, confessa-se desprovido de meios para tal empreitada. O que procura realizar é "apenas situá-lo, compreender esse transbordamento de que é objeto", nele, a noção de leitura. Para iniciar o seu trabalho lança mão do procedimento que possibilitou o avanço da Lingüistica: a noção de pertinência.

A pertinência ć, em Lingüística, o ponto de vista sob o qual se escolhe olhar, interrogar, analisar um conjunto tão heteróclito, dispar, quanto a linguagem. Somente quando Saussure passou a encarar a linguagem sob o ponto de vista do sentido, e só desse ponto de vista, ele parou "de marcar passo" e pode fundar uma nova Lingüistica. Foi aceitando, em detrimento de uma infinidade de considerações possiveis, apenas ver, em centenas de contos populares, situações e papćis estáveis, recorrentes, em suma, formas, que Propp fundou a análise estrutural da narrativa.

Conjecturando sobre a decisão por uma pertinência, sob a qual interrogaríamos a leitura, Barthes fala sobre desenvolver passo a passo uma Análise da Leitura (Anagnosologia, anagnose). É possivel detectar, no campo da leitura, a inexistência de uma pertinência de objetos: o verbo ler, "aparentemente muito mais transitivo do que o verbo falar, pode scr saturado, catalisado, com mil objetos diretos": leio textos, figuras, cidades, rostos, gestos, cenas, etc. Esses objetos são tão variados que é impossível unificá-los sob alguma categoria substancial, ncm mesmo formal; pode-se apenas encontrar neles uma unidade intencional: "o objeto que cu leio é fundado apenas pela minha intenção de ler; ele é simplesmente: para ler, legendum, pertencendo a uma fenomenologia, não a uma semiologia".

Barthes acusa também a falta de pertinĉncia de níveis no campo da leitura, scgundo ele, o mais grave. Não há possibilidade de descrever em níveis de leitura, porque inexiste a possibilidade de fechar esses niveis de leitura. Ele reconhece que há uma origem da leitura gráfica: é o aprendizado das letras, das palavras escritas. Por um lado, há leituras sem aprendizagem; como exemplo, cita as imagens, que não passam por uma aprendizagem técnica, senão cultural.

$\mathrm{O}$ segundo ponto abordado por Barthes é o recalque. Ele aponta dois tipos de recalque que estão relacionados com a leitura. $O$ primeiro está relacionado com as injunçöes, sociais ou interiorizadas por diversos processos de substituição que tornam a leitura um dever em que o próprio ato de ler é determinado por uma lei: o ato de ter lido. Não estão sendo discutidas aqui as leituras instrumentais, que são necessárias à aquisição de um saber, de uma técnica $\mathrm{e}$ nas quais o gesto de ler se dilui no ato de aprender. $O$ que está sendo discutido são as chamadas leituras livres, que, no entanto, é necessário terem sido feitas. No nosso caso essa necessidade esta fundada na expectativa de que o aluno que venha freqüentar um curso de Letras tenha feito determinadas 
leituras, que ele tenha tido acesso aos cânones da Literatura. Espera-se que tenha lido os românticos, realistas, modernistas e os pós-modernistas. Essa lei é proveniente de instâncias diversas, fundamentadas cada uma em um valor. A lei de leitura não provém de uma eternidade da cultura, mas de uma instância estranha, ou pelo menos enigmática ainda, situada na fronteira entre a História e a Moda. O que se quer dizer com isso é que existem leis de grupos, microleis, de que é preciso ter o direito de se livrar. A liberdade de leitura na concepção barthesiana, e não importa o preço que se tenha que pagar, é também a liberdade de não ler.

O segundo tipo de recalque que Barthes aponta é o da Biblioteca. Não há no seu reconhecimento nenhuma intenção em contestar ou negar o desenvolvimento desse espaço: trata-se de reconhecer apenas e simplesmente a marca de recalque existente nesse traço fundamental $\mathrm{e}$ inevitável da Biblioteca pública: a sua facticidade (caráter próprio da condição humana pelo qual cada homem se encontra sempre já comprometido com uma situação não escolhida). Para Barthes, a facticidade não é em si uma via de recalque; "se a Biblioteca pública se opõe ao Descjo de ler é por duas razões": independente de suas dimensões, a biblioteca está sempre aquém ou além da demanda: a tendência é nunca estar lá o livro desejado, ao passo que outro livro é proposto. A biblioteca instaura-se como o espaço dos substitutos do desejo. Sempre grande demais ou pequena demais, cla é:

fundamentalmente inadequada ao Desejo; para tirar prazer, plenitude, gozo de uma biblioteca, o sujeito tem de renunciar à efusão de seu Imaginário; é preciso que tenha feito seu Édipo esse Édipo que não se deve fazer apenas aos quatro anos de idade, mas a cada dia da minha vida que eu desejo. Nesse caso é a profusão mesma dos livros que é a lei, a castração.

A outra razão que Barthes aponta de oposição ao Desejo é a relação que estabelecemos com a Biblioteca. A Biblioteca é um espaço que se visita, mas não é um espaço que se habita. Ele se ressente da não-existência de uma palavra que distinguisse o livro de biblioteca, livro-objeto de uma dívida, mediado por uma relação burocrática ou magistral e outra para livro-em-casa, livro-objeto de um desejo ou de uma demanda imediata, livre de mediaçāo. O livro-em-casa não se configura como um pedaço de descjo puro; cle, de maneira geral, passou pela mediação do dinheiro; foi necessário comprá-lo. Do ponto de vista barthesiano, o dinheiro funciona como um meio de desrecalque. Tomar emprestado seguramente não o é; na utopia fourierista os livros quase nada valem, mas 
passam mesmo assim pela mediação de alguns tostões; são cobertos por um Dispêndio e desde então o Desejo funciona: algo é desbloqueado.

Que há de desejo na leitura? O desejo está impossibilitado de nomear-se c até mesmo de dizer-se. Barthes vê como certa a existência de um erotismo na leitura, pois na leitura, o desejo está presente junto com o seu objeto, o que é a definição do erotismo. Como forma de exemplificar esse crotismo da leitura Barthes utiliza o episódio de Em busca do tempo perdido, no qual Proust mostra o narrador se fechando no gabinete sanitário de Combray para ler.

Destinada a um uso mais especial e mais vulgar, essa peça, de onde se via durante o dia até o torreão de Roussanville-le-Pin, por muito tempo serviu de refúgio para mim, sem dúvida por ser a única que me era permitido fechar, para todas aquelas de ninhas ocupações que exigiam inviolável solidão: a leitura, o cismar, as lágrimas e a volúpia (Proust, 1992, p. 29).

A leitura desejante surge, então, portadora de duas caractcrísticas fundamentais. Ao praticar ato de trancar-se para ler, ao tornar a leitura um gesto absolutamente apartado, clandestino, no qual o mundo inteiro é absorvido, o leitor identifica-se com dois outros sujeitos humanos, extremamente próximos um do outro, cujo estado implica sempre numa separação violenta: o sujeito apaixonado e o sujeito místico. Teresa de Ávila é o exemplo utilizado para o sujeito mistico, pois ela fazia, de forma claramente expressa, da leitura um substituto da oração mental. No que diz respeito ao sujeito apaixonado, esse é caracterizado por uma completa demissão da realidade, por um investimento num mundo totalmente subjetivo. É legítimo reconhecer nesse paralelo entre o sujeito místico e o sujeito amoroso uma confirrnação de que o sujeito-leitor é um sujeito totalmente desterrado sob o registro do imaginário. Toda a sua cconomia de prazer está voltada para a sua relação com o livro "isto é, com a Imagem". O que se instaura então é unna relação narcisica entre leitor e livro. $O$ gabinete com perfume de íris onde se tranca o narrador proustiano é a própria clausura do Espelho, a cena onde se realiza a coalescência edênica entre o sujeito e a Imagem - "do livro".

$\mathrm{Na}$ leitura, todas as emoções do corpo estão presentes e embaralhadas, e essa é a segunda caracteristica da leitura desejante: o deslumbramento, a vagância, a dor, a volúpia. A leitura é o lugar da produção do corpo transtornado, mas não despedaçado. A leitura seria o lugar onde a estrutura se descontrola, pois ler não é um ato desprovido de intenção, é um ato doloroso, dramático, que exige do leitor paciência e obstinação, a fim de que ele possa superar o intenso 
conflito entre ele e o texto, conflito esse representado por uma imensa vontade de compreender, de concordar, de discordar - enfím, aquele que lê não capta no texto somente aquilo que o texto propõe, mas transmite ao texto lido as cargas de sua experiência humano-existencial.

Sem se ausentar do gabinete de leitura proustiano, Barthes procura mapear uma tipologia do prazer de ler. A sua inquietação sobre a possibilidade dc existência de prazeres diferentes de leitura leva-o a afirmar a existência de pelo menos três caminhos pelos quais a Imagem de leitura pode capturar o sujeito-leitor.

No primeiro modo, encontra-se um leitor que estabelece com o tex to lido uma relação fetichista: extrai prazer das palavras, de determinadas palavras, certas construções frasais; o texto constitui-se como lugar onde o sujeito-leitor se abisma, se perde: instaura-se entre o leitor e o texto uma relação mediatizada pelo erotismo da palavra.

No segundo, que se encontra totalmente oposto ao primeiro, o leitor $\dot{e}$ arrebatado ao longo do livro por uma força que está sempre, $\mathrm{cm}$ maior ou menor grau, dissimulada, "da ordem do suspense". O prazer, o gozo, resulta de um desgaste impaciente e arrebatador que o livro sofre. "Trata-se, principalmente, do prazer metonímico de toda narração, sem esquecer que o próprio saber ou a idéia podem ser contados, submetidos a um movimento de suspense".

Há, finalmente, o que Barthes chama uma terceira aventura da leitura. $O$ que ele nomeia como aventura é a forma pela qual o prazer chega ao leitor. Essa aventura da leitura é a Escritura. A leitura apresenta-se como condutora do Desejo de escrever. Não que isso signifique escrever tal e qual o autor cuja leitura nos contenta e satisfaz. O que desejamos é o desejo que o escritor teve de escrever, o desejo do autor pelo leitor, descjamos o ame-me, que é possível detectar em toda escritura. Citando Roger Laport, Barthes ressalta que uma leitura que não chame uma outra escritura é algo de incomprecnsivel.

Tomando a leitura por esta perspectiva, ela passa a ser entendida como produção, não mais de imagens interiores, de projeçōes, de fantasias, mas de trabalho. O produto consumido (texto) é recolocado no circuito cconômico da leitura sob a forma de produção possibilitando o desenrolar-se da cadeia dos desejos, cada leitura passa a valer pela escritura que ela produz, até o infinito. É lícito lembrarmos o fato de que nossa sociedade não é uma sociedade de produção, mas uma sociedade do ler, do ouvir e do ver, e não sociedade do escrever, do olhar e do escutar. Tudo está estruturado de forma que interponha um bloqueio à resposta.

O cineasta alemão Wim Wenders vem, já há algum tempo, se batendo contra esse bloqueio à resposta apontado por Barthes. Wenders tem se insurgido contra o que ele classifica como o vicio das imagens. Em scu último filme 
exibido no Brasil, Until the end of the World (Até of fim do mundo), Wenders tece uma dura crítica a valorização indiscriminada da imagem, simbolizada por pequenas máquinas que possibilitam que as pessoas possam ver, depois de gravados por um processo especial, os seus próprios sonhos. As pequenas máquinas de ver os sonhos do filme de Wenders são uma metáfora da vulgarização das imagens pela televisão e dos efeitos produzidos por esta nos espectadores.

Em Until the end of the world (Até o fim do mundo) caberá à palavra o papel de salvar a personagem principal do vício no qual ela se encontra mergulhada. Clair Torneur (Solveig Dommartin) vive num mundo completamente apartado, o mundo da imagem. Um mundo de fascinio que the arrebata o poder de atribuir sentido as coisas. Clair abandona a sua natureza "sensivel", abandona o mundo, retirando-se para aquém do mundo. Mergulha num abismo de luz em cujo fundo encontra-se um espelho que reflete a sua infância. A infância ć o próprio momento da fascinação, ela está imersa numa luz esplêndida. Para Blanchot essa luz é estranha à revelação, pois nada existe para revelar, não é mais que o brilho de uma imagem (1987, p. 24). O fascinio é o olhar da solidão, o olhar do incessante e do interminável. O que se tem nesse sentido é uma visão que já não é possibilidade de ver, mas impossibilidade de não ver: um olhar morto, convertido no fantasma de uma visão eterna.

A única maneira de trazer Clair para o mundo das possibilidades de significações é através da leitura. Utilizando esse artifício, Eugene (Sam Neal), namorado, escritor e também narrador do filme, isola Clair em uma espécie de prisāo ao ar livre, com o objetivo de livrá-la da doença das imagens. Para ajudar em sua recuperação, ele oferece à Clair o romance que acabara de reescrever em uma velha máquina Royal, pois o seu texto original se perdeu da memória do seu computador, quando o satélite nuclear indiano que ameaçava cair sobre, a terra explode na órbita do planeta. À medida que lê o romance Clair se recupera. É importante lembrarmos que essa leitura ocorre num espaço delimitado pela cerca que impede Clair de se perder na imensidão do deserto australiano. Assim como o leitor do gabinete sanitário de Combray, ela necessita, ainda que de uma forma simbólica, estar apartada do mundo para exercer a sua leitura. $O$ seu processo de cura. Clair é o próprio leitor arrebatado, aquele cujo prazer, o gozo, resulta de um desgaste impaciente e arrebatador que o livro sofre. Com o fim da leitura, Clair se recupera e Eugene a liberta. Com isso Wenders reafirma a sua crença na palavra como elemento de redenção da nossa humanidade. A leitura assume aqui um caráter positivo, estrutura-se como uma força poderosa e transformadora que está constantemente em renovação, pois cada vez que é executada ela se constitui numa nova leitura. Para Blanchot, somente o livro não literário se oferece como uma rede firmemente tecida de significações determi- 
nadas, como um conjunto de afirmaçōes que encontram legitimidade na realidade. O livro não literário passa por um processo de leitura prévia que the garante uma existência sólida, ele "já foi sempre lido por todos" (Blanchot, 1987, p. 195). Porém, o livro que tem a sua origem na artc não tem sua garantia no mundo, a sua leitura se faz a cada momento em que ć manuseado. Cada vez é a primeira e cada vez a única. É essa impossibilidade de uniformização da leitura que garante o desbloqueio à resposta. Mas enquanto esse desbloqueio não ocorrer, de forma efetiva, resta aos amantes da escritura a dispersão, a clandestinidade e o esmagamento por uma série de restrições, interiores. É necessário libertarmos a leitura, o que não será possivel, se no mesmo movimento, não libertarmos a escritura.

\section{RESUMO}

Este trabalho apresenta etapa de uma reflexão sobre a relação entre leitor, autor e obra; leitura, Desejo, Texto e Escritura a partir de signos barthesianos.

Palavras-chave: Escritura, Desejo, Leitura.

\section{RIASSUNTO}

Questo lavoro presenta una tappa di una riflessione sul rapporto tra lettore, autore e l'opera; lettura, Desiderio, Testo e Scrittura a partire da segni barthesiani.

\section{REFERÊNCIAS BIBLIOGRÁFICAS}

BARTHES, Roland. Da Leitura. In: O rumor da lingua. Tradução de Mário Laranjeira. Prefácio : Leila Perrone-Moisés. São Paulo : Brasiliense, 1988.

BLANCHOT, Maurice. $O$ espaço literário. Tradução: Álvaro Cabral. Rio de Janeiro: Rocco, 1987.

FERREIRA, Aurélio Buarque de Hollanda. Novo Dicionário Aurélio da língua portuguesa. 2. ed. revista e ampliada. Rio de Janeiro : Nova Fronteira, 1986. 
PROUST, Marcel. Em busca do tempo perdido: no caminho de Swann. Tradução: Eduardo Py. Rio de Janeiro : Ediouro, 1992.

REIS, Carlos; LOPES, Ana Cristina M. Dicionário de teoria narrativa. São Paulo : Ática, 1988. (Série Fundamentos). 